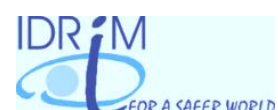

Original paper

\title{
Impacts of cognitive and behavioural biases on decision-makers prior to the 1995 Kobe, the 2004 Sumatra-Andaman and the 2011 Tohoku earthquakes
}

\author{
Nadejda Komendantova ${ }^{1},{ }^{2},{ }^{*}$ and Junko Mochizuki ${ }^{1}$
}

Received: 13/11/2015 / Accepted: 11/7/2016 / Published online: 21/09/2016

\begin{abstract}
The earthquakes, such as the 1995 Kobe, the 2004 Sumatra-Andaman and the 2011 Tohoku, showed the need of a multi-risk approach, which would include multi-risk assessment and multi-risk governance. Despite available international frameworks and implementation of a multi-risk approach in a number of regions, the disaster risk reduction is still dominated by the single risk approach, which does not take into consideration interactions among risks. This research is based on the behavioral economics and identified barriers in the individual decision-making processes for implementation of the multi-risk approach. Evidence of cognitive and behavioral biases was found in human reasons of decision-makers prior to all three above mentioned earthquakes. Our results showed that availability heuristics, loss aversion and limited worry were three most common biases, at the same time as experimental versus statistical evidence and bounded rationality were playing the least significant role in the decision-making process.
\end{abstract}

Key words: Multi-risk disasters; Disaster preparedness; Cognitive biases; Decision-making processes

\section{INTRODUCTION}

Recent earthquakes such as the 1995 Kobe, the 2004 Sumatra-Andaman and the 2011Tohoku were multi-hazard disasters and showed the need of a multi-risk approach (MRA). MRA takes into consideration multiple risks for development and the implementation of risk management and mitigation strategies. It goes beyond the multi-risk assessment and also involves multi-risk governance.

Even though MRA is a relatively new movement in disaster risk reduction practice, the history shows examples that the need for this was already discussed several years ago. The well-known example is the 1756 earthquake, which struck Lisbon. It was followed by fire and tsunamis, which killed 60.000 people.

\footnotetext{
${ }^{1}$ International Institute for Applied Systems Analysis (IIASA), Schlossplatz 1, A-2361 Laxenburg, Austria

${ }^{2}$ Climate Policy Group, Department of Environmental Systems Science, Institute for Environmental

Decisions (ETH), Zurich, Switzerland

* Corresponding author: E-mail address: komendan@iiasa.ac.at
} 
At that time people blamed providence for disaster and destruction. More than two centuries have passed since the Great Lisbon earthquake and the discourse about disaster risk reduction, including research and innovation, progressed significantly. The volumes of knowledge have been growing as well as available data for risk assessment. However, despite this growing data the losses from disasters have also been growing due to several reasons (White et al. 2001). One of the reasons involves barriers to knowledge transfer from science to practice, namely, how risk assessment is perceived by decision-makers and then implemented in risk mitigation strategies (Kappes et al. 2012). The risk mitigation strategies are not only the result of technical and economic capabilities but also of human factors such as human decisionmaking and reasoning, which can be influenced by cognitive and behavioural biases (Kunreuther 2008). The reduction of risk cannot be based on scientific knowledge and risk assessment. Implementation of risk assessment and risk governance have also social dimensions (Assmuth et al. 2010). Therefore, it is crucial to bring knowledge together about risk assessment and human decision-making for successful implementation of the results of this assessment (Fleischhauer et al. 2007).

Evidence also shows that people make different estimations about how dangerous certain risks are and risk perceptions vary according to groups of stakeholders, such as scientists or decision makers (Douglas 1985). While cognitive and behavioural biases hampering risk reduction in the context of single hazard situations have been extensively studied (Patt and Weber 2013), the question about how cognitive and behavioural biases operate under additional complexity present within the context of multi-hazard risks remains largely unknown (Komendantova et al. 2013). The complexity regarding the assessment of probabilities and the mitigation of multiple hazards has been extensively documented (T6 2007). However, how such processes are affected by cognitive and behavioural biases are less well understood. This paucity of knowledge is, in fact, problematic, as disaster risk management policy should be formulated and implemented in a context of multiple risks. The efforts to manage one hazard should not blind decision makers from the need to manage another one.

The transfer of knowledge about multi-risk assessment can be hindered by individual decision-making and how stakeholders, who make decisions on risk mitigation strategies, perceive the probability and seriousness of different kinds of risks. Behavioural economics tell us that risk perceptions are influenced by cognitive and behavioural biases. The cognitive and behavioural biases are part of risk perceptions, which are subjective judgements of people about characteristics and severity of risk. The biases influence the process of knowledge transfer from science to practice and policy and have consequences on implementation of risk mitigation and management strategies. The main aim of this study is to answer two research questions. First, is there evidence that decision-making processes at the level of local governments are influenced by cognitive and behavioural biases? And the second one, if so, when and how frequently were the following six biases mentioned the most frequently in the published literature about 1995 Kobe, 2004 Sumatra-Andaman and 2011 Tohoku earthquakes: i) availability heuristics, ii) loss aversion, iii) limited worry, iv) dread risk, v) experimental versus statistical evidence, and vi) bounded rationality.

Our research also aims to find out if there is evidence for two hypotheses. The first one is that with regard to estimations of probabilities for natural hazards and especially to giving priority for actions in case of multiple hazards, stakeholders are more motivated to solve problems, namely to settle risk mitigation strategies for risks which are born out of their personal experience than for risks which are communicated to them by scientists or analysts. The second one is that in multi-hazard situations the ambiguity aversion can lead to preference for known risks over unknown risks. In risk mitigation and management strategies the decision-makers would rather choose options with fewer unknown elements than with many unknown elements. This also will influence perceptions of stakeholders in regard to the risky and to the ambiguous events. 


\section{BACKGROUND}

\subsection{Multi-risk approach as part of risk governance}

Risk governance is a systematic approach to decision-making and policy processes, one of whose major aims is to reduce risk exposure and vulnerability as well as the human and economic losses caused by disasters (Renn 2008). Risk governance deals with the questions of how decisions are taken and implemented based on the assessment, management and communication of risks (IRGC 2011). The concept of risk governance also includes a multitude of stakeholders, and their views and perceptions of the risk.

The 1995 Kobe, 2004 Sumatra-Andaman and 2011 Tohoku earthquakes show that multi-risk environments are characterized by cascading effects, which include correlated phenomena between different risks and hazards. Several international frameworks called for implementation of MRA and the need to recognise MRA by decision-makers. The Hyogo Framework for Actions (HFA) emphasises the necessity to develop and strengthen research methods and tools for multi-risk assessment (UNISDR 2005). The 2015 Sendai Framework for Disaster Risk Reduction, which highlights benefits of multi-risk approach. The review of efforts to implement MRA, which was conducted in frames of 2011-2013 HFA Regional Synthesis, showed that there are still barriers for implementation of results of MRA and that the progress in this area is very limited (UNISDR 2013). Nowadays, most of the risk governance frameworks are centred towards a single risk approach despite commitments of international frameworks and the single hazard assessment is till the norm.

Originally, MRA was defined in the literature as a joint analysis and quantification of all anthropogenic and natural risks that could affect a territory and should be a precondition for sound environment management, land use planning, and competent emergency management before and during catastrophic events (Durham 2003). In the disaster risk reduction discourse, MRA is understood as an approach, which takes into consideration interdependencies between multiple risks, which can trigger a chain of natural and manmade events with different spatial and temporal scales (Marzocchi et al. 2012; Garcia-Aristizabal et al. 2013). MRA was further developed in the Multi-Hazard and Multi-Risk Assessment (MATRIX) Methods for Europe project.

\subsection{Cognitive and behavioural biases}

Despite growing knowledge on methodologies for MRA, there are relatively few scientific works about implementation of MRA. The Principles of Multi-Risk Assessment, Interaction among Natural and Man-Induced Risks (NaRaS) project conducted an MRA for the Casalnuovo municipality in Southern Italy. It showed that policy stakeholders perceived one risk, the volcanic one, as being most serious and that mitigation of this risk overwhelmed all other risks such as industrial or environmental which resulted in underestimation of these risks (Marzocchi and Woo 2009). But the question remains open why they perceived some risks as being most probable.

The ambiguous events, such as low probability but high impacts hazards, are perceived with a greater degree of uncertainty of outcomes and probability to happen (Patt and Weber 2013). The perceptions about outcomes and probability are influenced by biases, which cause decision-makers to underestimate the probability of disaster and to underestimate its effects. The risk perceptions are often connected with risk mitigation strategies when people fail to prepare for a disaster. It is especially tragic when the government fails to prepare the population of its country under an assumption of low probability of the risk. This assumption makes people unable to react properly in a disaster situation in which they were not confronted with before, and to properly prepare themselves for a disaster. Being overoptimistic, decision- 
makers might disregard warning signals and overestimate their control over the situation. They might also stop worrying about events which are perceived as less probable leading to decision making which will results in inadequate shelter, supplies and evacuation plans. The excessive optimism reduces the willingness of decision-makers to search for further information on low probability events. The overconfidence of decision-makers may lead to ignorance of low probability events and to false decisionmaking, resulting in gaps in risk mitigation measures. Below we list cognitive and behavioural biases and provide review of existing literature on evidence of these biases.

The bounded rationality bias manifests when an individual decision-maker is limited by the information available to make decisions. Under these constrains, a decision-maker may 'satisfy' rather than 'optimize' when they choose a good enough option that meets their basic criteria (Lindblom 1959). The bounded rationality bias is known to lead to sub-optimal risk reduction within the context of singlehazard risk. Under time and cost constraints, the decision-makers are simply searching for a solution until they reach a certain acceptable level of performance. While such decision-making heuristics may be helpful in the context of highly uncertain and complex situations, this type of bias may lead to potentially devastating errors.

The experimental versus statistical evidence bias is also known as the base rate fallacy. This bias manifests when people make their own judgments regarding the probability of an event under uncertainty. Studies have documented that people prefer information, which addresses emotions or which was experienced personally, instead of general or statistical information, even in cases when the latter is available. This bias may also be referred to as representativeness heuristics, when people make decisions based on the 'representativeness' of an event, where representativeness is defined as "the degree to which an event is similar in essential characteristics to a major event, and reflects the salient features of the process by which it is generated" (Kahneman and Tversky 1979). A wrong judgment may result from such heuristics, since more representative does not necessarily make it more likely than another event. This bias is connected with such features as similarity. Under similarity, by judging the representativeness of a new event, people usually pay attention to the degree of similarity between this event and a standard event. It is also strongly influenced by memory, when concrete examples are stored in memory and are influencing judgments about the probability of an event.

The dread risk bias is connected with the judgment of people about the unknown risk and their "perceived lack of control, dread, catastrophic potential, fatal consequences, and the inequitable distribution of risks and benefits" (Slovic 1987). The bias manifests when the expert judgments of risk run counter to the judgments of lay people. The risk of nuclear power accidents is a canonical example of dread risk bias. The majority of experts find nuclear power to be a relatively low risk technology, while at the same time the public finds it to be a high-risk technology. The Dread risk relates to emotions, which make people perceive consequences of an event as high because they don't have experience of its management. It is also connected with unknown risk, when the risk is perceived as new with unforeseeable consequences and not detectable exposure. Often this type of bias is connected with a new technology, marked by again unknown potential risks associated with it.

Availability heuristics is a bias in behaviour when people simplify their judgement based on how easy it is to recall similar events, when confronted with the difficult task of judging the probability or frequency of the event. The availability heuristics is closely linked to a decision-maker's perceptions regarding how often an event occurs, which is often influenced by the media coverage, etc. People tend to over-estimate the probability of an event when it is covered regularly in mass media. Under availability heuristics, the recent experience of a disaster influences strongly the perceptions of people on probability of a similar disaster in the future. This is also referred to as familiarity heuristics and suggests that the ability of stakeholders to see events as likely to happen depends on how easily they can recall specific past information associated with this event (Tversky and Kahneman 1974). Availability heuristics also leads to situations when people take uncertainties seriously, which relate to their personal and local experience. However, they have difficulties in perceiving uncertainties which relate to more global and 
abstract processes (Marx et al. 2007), or they focus primarily on short-term consequences, when they perceive a hazard as being less probable if it has not occurred for several years (Kunreuther et al. 1978).

The ambiguity aversion bias is connected to the limited worry bias in which people solve what they perceive as the most important problem and cease to worry about other problems that may in fact be as important, if not more so. This bias may also occur when people decide to solve issues with clear or known probabilities rather than vague or unknown probabilities. Stakeholders may also prefer to solve issues when they recognize themselves to be particularly competent or knowledgeable, rather than to solve issues with which they themselves feel incompetent (Heath and Tversky 1991). They perceive also more recent and more concrete risks as being the most important to mitigate (Trope and Liberman 1993).

The limited worry is also connected to a series of biases such as excessive optimism, overconfidence, confirmation bias and illusion of control. Under excessive optimism, stakeholders tend to overestimate the number of favourable outcomes in comparison to unfavourable ones (Shefrin 2007). Overconfidence occurs when stakeholders overestimate their abilities and underestimate the limits of their knowledge. In general, they tend to overestimate their ability to perform well, which results in impulsive decisions as stakeholders think that they know more than they really do. The confidence bias leads to interpretations of information in such a way that it confirms preconceptions, while avoiding interpretations that contradict previously held beliefs. This type of bias is regarded as the most "pervasive and potentially catastrophic" of the cognitive biases to which human fall victim to (Plous 1993). Another bias is positive illusion, when people are overly positive about themselves (Taylor and Brown 1988), and illusion of control, when people tend to behave as if they had control over the situation at hand, which they may not have in reality, or they overestimate how much control they have (Gino et al. 2011). The illusion of control results in the belief of decision-makers that they can control or influence outcomes that are in reality out of their influence.

The loss aversion bias is expressed in behaviour of stakeholders when expected losses are perceived as being greater than potential gains, therefore it expresses a stronger desire to avoid losses than to experience comparable gains (Tversky and Kahneman 1992). Actually, losses are emotionally felt much stronger by stakeholders compared to possible gains. The risk aversion is often combined with the sunk costs fallacy, in which stakeholders attempt to minimize already wasted resources rather than maximizing future utility. This is also related to the 'status quo bias', when a decision-maker prefers the current situation and does not wish to take any action to change the status quo. Existing studies indicate that for low probability but high impact hazards, the stakeholders are known to be risk seeking for gains and risk averse for losses, whereas they are risk averse for gains and risk seeking for losses associated with high probability events (Tversky and Kahneman 1992).

\section{METHODOLOGY}

In multi-risk science, the decision-making process of stakeholders is often described in terms of "how the decision should be made" instead of "how the decision is made in reality". To our knowledge, there is no evidence in scientific literature on on-going research or results about how cognitive biases are influencing perceptions of probabilities of different risks, and further on, influence decision-making process on risk mitigation measures in multi-risk environments. To understand historical decision-making processes of local governments prior to three multi-hazard disasters our methodology included the following steps:

- $\quad$ Literature review

- identification of cases through interviews and validation of interview results in the frame of focus group discussions 
- content analysis of these cases in the literature

We collect empirical data on decision-making processes in three case studies with literature review of mainly currently existing research in engineering. The majority of existing research on historical multiple hazards events was conducted in engineering and mathematics. The number of papers published in social sciences on multiple hazards events is minimal.

To identify relevant cases we conducted interviews with experts on disaster risk reduction. As a result we got recommendations on several cases. We discussed the cases in frame of a focus group discussion, which was conducted in April 2012 among participants of the Multi-Hazard and Multi-Risk Assessment Methods for Europe (MATRIX) project at the premises of IIASA, in Laxenburg, Austria.

The focus group discussion allowed us to narrow the choice of case studies to four major events, which are highly relevant for multi-hazard risk management. These events are i) the Messina earthquake of 1908, ii) the Kobe earthquake of 1995, iii) the Sumatra-Andaman earthquake of 2004, and vi) the Tohoku earthquake of 2011. However, during the following up research we could collect robust data and sufficient number of data sources for only three cases including the 1995 Kobe, the 2004 SumatraAndaman and the 2011 Tohoku earthquakes. Sufficient evidence was not available for the case of Messina earthquake, which happened more than one hundred years ago. After the initial review of the four cases identified, we decided to exclude the Messina earthquake from our content analysis as there was not sufficient documentation regarding this event. We provide a short description of the cases below.

After the major earthquake during the Messina earthquake and tsunami of 1908, people tried to seek refuge near the city's harbour. However, soon after the harbour was inundated by a tsunami which was caused by the earthquake, and killed even more people. This example suggests that people were not aware that earthquakes can also cause tsunamis. The failure in decision-making was not caused by cognitive or behavioural biases, but by the deficiency of knowledge existing at that time.

In the Kobe area prior to the Kobe earthquake of 1995, the buildings were constructed with the use of heavy roofing material in order to make them able to withstand heavy winds as the city suffered periodically from tropical cyclones. However, heavy roofs make buildings more vulnerable to earthquake damage. Even though the earthquake planners addressed other aspects of building construction, such as the traditional use of wood frames rather than unreinforced masonry support structures, they failed to consider roofing design. The decision to use heavy roofing materials may have been a response, either explicitly as a result of risk assessment for cyclone hazards or implicitly as a result of evolved building practices, to the risk of cyclones. But as earthquakes was rare, this resulted in a failure to consider the additional damage that heavy roofs could cause in the event of earthquakes.

During the 2004 Sumatra-Andaman and the Indian Ocean tsunami, for example, in India, people could have fled to emergency cyclone shelters to avoid the approaching tsunami, While an early warning system was set up to warn of approaching cyclones, giving people the opportunity to seek refuge in the shelters, the system was not designed to warn of tsunamis, and so people did not take advantage of the shelters that were there. This could have resulted from simply a failure to take into account tsunami risk at all. Nevertheless, this may have been the result of poor judgment at the time of constructing the shelters, as it would have been more appropriate to consider all risks for which they could be used, including making the minor additional investment in a warning system to respond to tsunamis.

Prior to Tohoku Earthquake, Tsunami, and Nuclear Accident of 2011, the risk analysts took into account the risk of tsunami, but failed to evaluate its possible height. The earthquake shut down the reactors and the tsunami caused by the earthquake resulted in a devastating flood, that damaged support systems. In fact, it appears that this contingency was examined, but that the estimates of the size of a possible tsunami were simply inadequate, given the relatively poor state-of-the-art of oceanographic modelling at the time the nuclear plant was constructed, compared to today. The plant designers also 
chose to locate the nuclear station on the coast, rather than inland, in order to be able to build on the more stable bedrock that the coast offered, thus taking precautionary steps for an earthquake, but not a tsunami. In fact, there is reason to believe that the primary motivation for building on the coast was to take advantage of unlimited seawater for the secondary cooling system. Hence, the roots of the nuclear accident - the decision to locate the backup diesel generator, needed for the emergency reactor cooling system, in the basement, which was flooded-was an overconfidence in the degree to which the constructed seawall would guard against a tsunami risk. This was unrelated to the multi-hazard nature of the accident.

As a major method of our research we use content analysis. Content analysis is often used for interpretation of documents, which are provided in frames of communication process. This method is used to identify evidence from texts (Hodder 1994). Content analysis appeared as a reaction to human attitude read the texts selectively, in support of expectation, which someone has before reading the text. This method allows researchers to identify systematically properties of the text, such as frequency of most used words.

Content analysis is often used for interpretation of documents, which are provided within framework of the communication process. This method is used to identify evidence from texts (Hodder 1994). Context analysis appeared as a reaction to the human attitude of reading texts selectively in support of expectations, which someone had before reading the document. This method allows researchers to identify systematically properties of the text, such as the frequency of the most used words. In order to implement content analysis and text-mining, we gathered media reports, grey literature, reports from national and international entities on the management of multi-hazard risk and recovery phases, reports from investigation commissions and scientific papers. Altogether we reviewed 28 reports published on the 1995 Kobe earthquake, 20 of which were from the mass media and grey literature, and 8 were sources listed and published in Scopus with research from different scientific disciplines, 276 reports published on the 2004 Sumatra-Andaman earthquake, of which 245 were messages and printed evidence from the media and 32 were peer-reviewed papers and reports, and 74 printed sources on the 2011 Tohoku earthquake, from which 65 were printed media texts and reports and 9 were peer-reviewed papers published in Scopus.

\section{RESULTS}

Our results showed that the decision-making process prior to the three multi-hazards disasters, discussed in this work, was a subject to cognitive and behavioural biases. These biases influenced the perceptions of seriousness of risk and its probability. The risk perceptions resulted in the implementation of decisions, which made infrastructure more vulnerable to not-perceived risk or that measures to mitigate additional risks were not implemented. The empirical documentation suggests that a number of cognitive and behavioural biases have led decision-making processes in which an attention toward mitigation of one risk and made them to overlook other risks. The following section describes in detail cognitive and behavioural biases identified in each case.

\subsection{Kobe earthquake of 1995}

Altogether we analysed 28 reports, studies and media evidence on the Kobe earthquake. The context analysis shows that loss aversion was mentioned by published sources most frequently (in 23 of these documents), followed by limited worry (18), availability heuristics (17), bounded rationality (12) and experimental versus statistical evidence (5) (Figure 1). The effects of these biases are intricately linked in the case of Kobe earthquake, as the region has traditionally been characterised by high exposure to 
seasonal typhoons, which encouraged the local population to adopt heavy roofing material, in order to make buildings able to withstand heavy winds. While these heavy roof materials widely adopted in the traditional housing design in Japan have been repeatedly identified as being 'vulnerable' in the context of earthquake risks, a number of cognitive biases, including loss aversion and limited worry biases prevented the local population making appropriate precautionary measures. Despite the high earthquake risk of metropolitan Tokyo frequently portrayed in mass media, the local residents and policy-makers failed to recognize the imminent danger to their own community of Kobe. These inter-linkages hence created additional inertia of society, whereby people continued to underestimate the risk of earthquake.

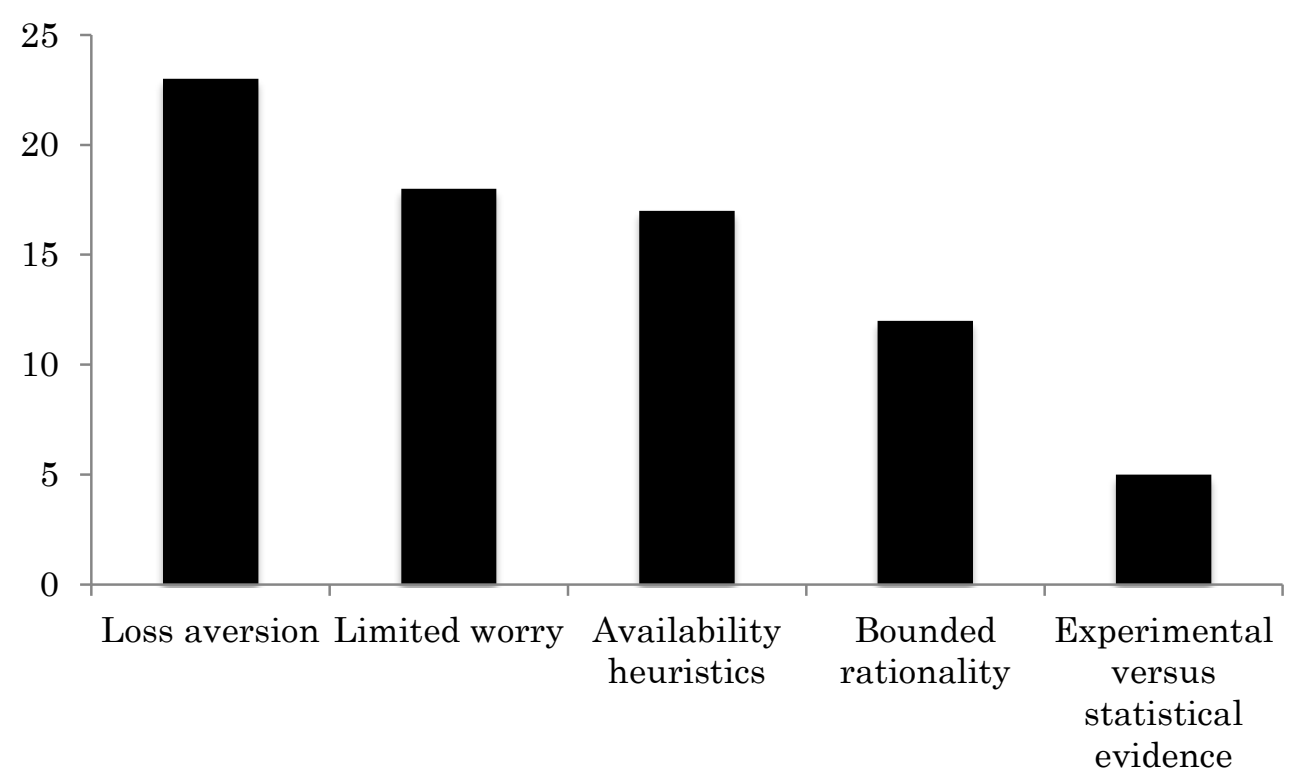

Figure 1. Evidence of cognitive and behavioural biases in decision-making prior to the Kobe earthquake of 1995 (number of identified cases out of 28 reports).

As the availability heuristics was mentioned most frequently in the reports, it seems that limited worry also played one of the major roles in the implementation of risk mitigation measures. In Kobe prior to 1995, the limited worry bias made decision-makers mitigate against one type of hazards and ignore another. The buildings in Kobe were constructed in a way to withstand typhoons -- the most frequent hazards in Kobe --and they were not designed to withstand earthquakes. Most of traditional houses had heavy tiled roofs, which weighed around 2 tons. When the wood supports were destroyed, the roof crushed the unreinforced walls and floors, causing what is termed "pancake" collapse of $10 \%$ of all houses in Kobe (mostly built prior to 1970 based on the old building code). More than $80 \%$ of all human losses were caused in the early stages of the earthquake because of the collapse of such houses and buildings. Due to the limited worry bias, some structures were reinforced after the 1971 San Fernando and 1964 Niigata earthquakes, however the large number of old wooden houses was not refurbished (Katayama 2004). As a result, the earthquake in Kobe caused much more significant damages than a similar hazard, the Northridge earthquake, which occurred one year earlier in Los Angeles with a similar magnitude of 6.7. The density of population was also roughly the same with about 2 million in both the Kobe area and the San Fernando Valley of Los Angeles. However, in the Northridge earthquake only 72 people died while more than 6,000 people died in Kobe.

Limited worry also expressed itself in the belief of Japanese officials that infrastructure is resistant to 
earthquakes. This belief was caused by the fact that since the Kanto earthquake in 1923, all new infrastructure was designed to stand large static horizontal forces. The seismic factors of 0.2 to 0.3 were considered to be four to five times greater than those used in US structures constructed before the 1971 San Fernando earthquake. This was the major reason why Japanese decision-makers perceived Japanese infrastructure to be more earthquake resistant than similar US infrastructure

The availability heuristics bias was found to have led decision-makers to underestimate the danger of earthquake, which had not taken place in the recent past in the region. For example, for more than 50 years no large earthquake had occurred in the large cities of Japan, while some experts believed that the Japanese cities had became earthquake resistant, even though many policy-makers in other places still worried about earthquakes prior to 1995 (Shimazaki 2011).

The content analysis also indicated that experimental versus statistical evidence bias may have marked the behaviour of stakeholders, when they interpreted facts dependent upon their level of knowledge and not on analytical or statistical information. Before the Kobe earthquake happened, few people imagined that such devastating earthquake could strike the Kansai region with the total population of the cities of Osaka, Kyoto and Kobe. The attention of risk management authorities was focused on plate boundary earthquakes taking place in subduction zones such as Nankai, where the Japanese national government placed priority on expected earthquakes. This led to a situation, in which almost all antiearthquake policies were focused on the Kanto area, with a special emphasis on Tokyo. The region of Kansai was a blind spot where officials and population remained unprepared. The majority of people thought about the Kanto region, with all risk mitigation measures directed to this region of Japan because of the large and repeated earthquakes that hit this region, including the Great Kanto Earthquake of 1923 and a few other earthquakes, which happen periodically in Tokyo.

Finally, we also found evidence of the bounded rationality bias, when decision-makers were limited in their ability and desire to collect information due to time or resources constraints. They believed in the seismic mitigation measures taken were good due to progress in science, earthquake engineering and technology. Also, the economic and technological progress in the country made them to believe that structures became strong enough to outlive the most violent ground motions. The majority of stakeholders in Japan tended to think that structures in Japan are strong enough to resist the most powerful earthquakes, like those that happened in Tokyo and Yokohama in 1923. The misleading perception was caused by the fact that, while indeed technology had progressed significantly, no strong earthquakes happened nearby the large urban centres after the Kanto earthquake. Even though the structures might have been strong enough, the possible destruction of urban infrastructure was not taken into account. The policy - makers were bound in their rationality to see only infrastructure which needed to be protected.

\subsection{Sumatra-Andaman Earthquake and Indian Ocean Tsunami of 2004}

W The population of India and Bangladesh could have fled to emergency shelters to avoid the approaching tsunami, but this did not happen for several reasons. First, despite several years of experience in the construction of cyclone shelters in such countries as India and Bangladesh, their number was still not sufficient in the region and they were not adapted for tsunami and flooding. With additional technical equipment and investment, these shelters could have been used for the case of tsunami. However, additional investment to adapt shelters from single-hazard to multi-hazard situation was regarded as too costly by local decision-making process.

Also, prior to the Sumatra-Andaman Earthquake and Indian Ocean Tsunami of 2004, tsunamis were perceived as being a low probability event, which did not provide a justification for investment in tsunami risk mitigation measures. Furthermore, the existing early warning systems did not work for tsunamis because they were oriented towards different hazards, primarily cyclones. The Sumatra-Andaman Earthquake and Indian Ocean Tsunami of 2004 also illustrated the added complexity of cognitive and 
behavioural biases within the context of multi-hazard risks.

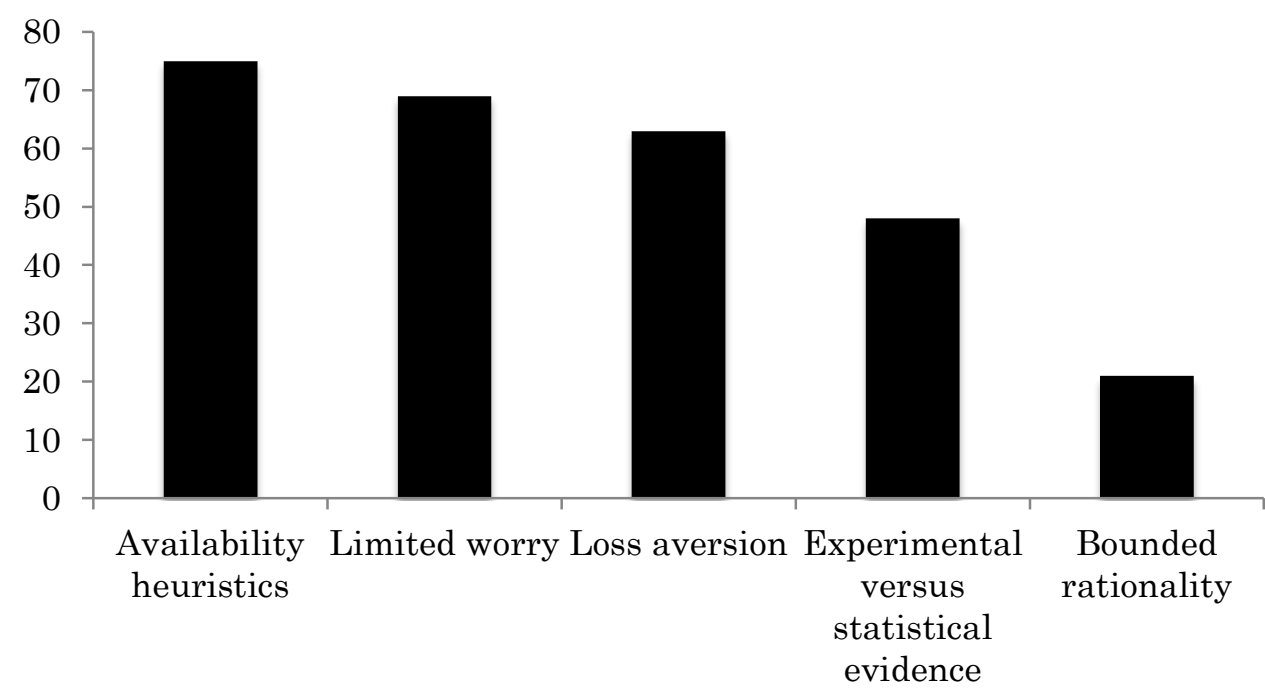

Figure 2. Evidence of cognitive and behavioural biases in decision-making prior to the Sumatra-Andaman earthquake of 2004 (number of identified evidence out of 276 reports).

Out of 276 printed sources of information, availability heuristics were mentioned most frequently (75 times), followed by limited worry (69), loss aversion (63), experimental versus statistical evidence (48) and bounded rationality (21) (see Figure 2).

We found evidence that availability heuristics strongly influenced the decision-making process prior to these events. Decision-makers in the countries affected by the disaster, namely in India, perceived the probability of tsunami as low because they were lacking recent experience. The last major tsunami occurred in 1883 after the Krakatau eruption. While the decision-makers perceived earthquakes as highly probable in the countries around the Indian Ocean, they perceived the underwater earthquake and tsunami as less probable because it had not happen for almost one hundred years.

The limited worry bias was identified where risk mitigation measures were taken for a more probable event, overlooking the danger of tsunami risks. In recognition of immanent cyclones, the risk mitigation measures in the region primarily focused on the construction of cyclone shelters and early-warning systems for cyclones. These cyclone shelters could have been adopted also for the case of tsunamis with only a little additional investment, however, as tsunami was perceived as improbable, the cyclones were not adopted for the case of tsunami.

We also identified that the loss aversion bias motivated decision-makers to invest into mitigation of well-known, highly probable risks to prevent losses. However, they perceived investment into the mitigation of risk that they perceived as having a low probability as unnecessary. The loss aversion is connected to the status quo bias, when potential losses are perceived as being greater than potential gains. This leads the decision-maker to prefer the current situation and not to take any action to change the status quo. For example, despite the 40 years of experience with the construction of cyclone shelters and existing practices for the adaptation of these shelters to multi-purpose shelters, investment into the adaptation of these shelters to tsunamis was perceived as being a greater loss in the present rather than a possible gain in the future.

The experimental versus statistical evidence bias influenced the decision-making regarding the estimation of probabilities of tsunami and earthquake. Decision-makers have perceived the high probability of earthquakes and tsunamis in the Pacific Ocean, as it is famous for its "Ring of Fire". 
Therefore, an effective early warning system was established in the Pacific Ocean. The possibility of underwater earthquake and tsunami in the Indian Ocean, on the other hand, did not fit to the picture the decision-makers had. This bias therefore influenced the decision-making process in India with regards to the communication of the results from risk assessments. The historical evidence shows that several numerical models of earthquakes in the region alerted seismologists about possibility of a great underwater earthquake in the region. However, despite the possibility of tsunamis, there was a failure in establishing a warning system before the event. The experimental versus statistical evidence bias made decision-makers deal with the types of hazards they felt themselves to be competent and knowledgeable in, like earthquakes occurring on land. However, they failed to establish the early warning system for undersea earthquakes, even after the results of risks assessments by seismologists on probability of such events were issued.

The bounded rationality bias is often caused by time constraints when decision-makers are choosing simplified solutions. This bias may have influenced the communication process of risk. It is known that the early warning system, which operated in the Pacific Ocean, was sending messages about the probability of an undersea earthquake in the Indian Ocean, however, these messages were not communicated to inhabitants of communities close to the shore and no action was taken to mitigate against this type of risk and to prepare population for a possible disaster.

\subsection{The Tohoku Earthquake of 2011}

All together we analysed 74 documents on the Tohoku earthquake. The content analysis showed that overconfidence was mentioned most frequently (26 times), followed by availability heuristics (24), bounded rationality (10), loss aversion (8), dread risk (6) and limited worry (3) (see Figure 3).

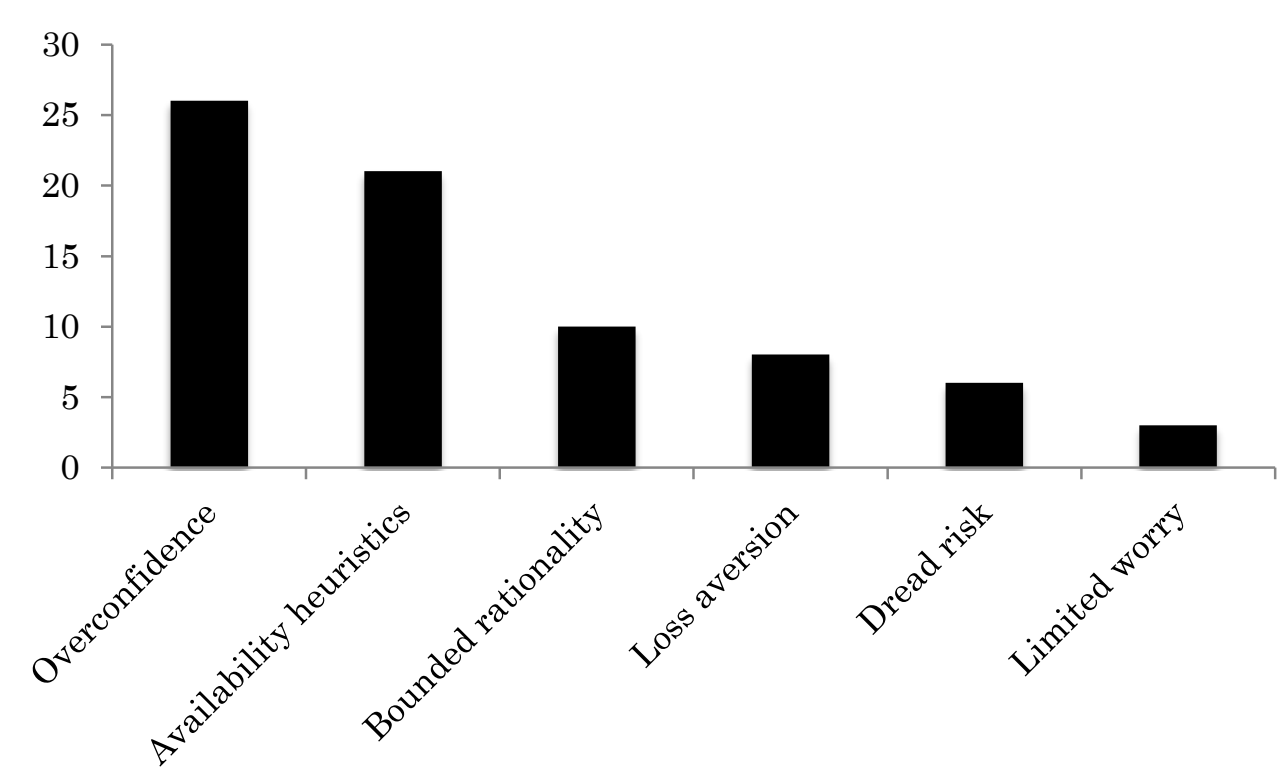

Figure 3. Evidence of cognitive and behavioural biases in decision-making prior to the Tohoku earthquake of 2011 (number of identified evidence out of 74 reports).

The Tohoku Earthquake of 2011 was characterized by a number of failures to take a multiple hazard into consideration. First, the nuclear power plant risk analysts failed to take into account the fact that an earthquake could cause a tsunami, leading to both a shutdown of the plant from the earthquake and a 
devastating flood. In fact, it appears that this contingency was examined, but simply that the estimates of the size of a possible tsunami were inaccurate, given the relatively limited oceanographic modelling at the time the nuclear plant was constructed, over 40 years ago, compared to today.

Second, the plant designers were overconfident in the degree to which the constructed seawall would guard against a tsunami risk. To take advantage of unlimited seawater for the secondary cooling system, they chose to locate the nuclear plant on the coast with more stable bedrock, a precautionary step in the event of an earthquake. Given the coastal setting, designers did take tsunami risk into account, but underestimated the size of the tsunami. This eventually led to a problematic decision to locate the backup diesel generator, needed for the emergency reactor cooling system, in the basement, which was flooded by tsunami. The Tohoku Earthquake of 2011 therefore demonstrated the added complexity of cognitive biases that operate under multi-hazard risk situations.

The overconfidence bias was most frequent cited and this mostly regarded the belief in the reliability of the nuclear power plant. Prior to the Tohoku earthquake of 2011, the design of the nuclear plant was carried out using deterministic risk evaluations. According to this approach, the decision-makers assumed critical situations for important safety functions and provided sufficient safety margins for these situations.

In the case of the Fukushima Daiichi nuclear plant, all safety regulations were developed on the basis of the deterministic approach and the probabilistic approach was treated only as supplemental information. There are three reasons for this. First, experts perceived the failure probability to be low enough. Second, they perceived the probabilistic approach to be not technically mature enough. Third, experts were more confident about deterministic analyses over probabilistic analysis, overconfidence led to a blind belief in the validity of their deterministic risk assessment.

The content analysis also indicated that the availability heuristics influenced estimations of tsunami heights. In some parts of the Tohoku coast, the tsunami was much higher than those typically observed in the recent past. The large size of the water surge was among several factors which caused the high death toll. The tsunami walls at several of the affected cities were based on estimations for much smaller tsunami heights (Cyranoski 2012). This not only caused massive destruction, but also significant human losses. Many people were caught in the tsunami, thinking that they were safe because they were located on protected ground, which is usually high enough to be safe (Japan Times 2011). This resulted in only $58 \%$ of people in the coastal areas of Iwate, Miyagi and Fukushima prefectures heeding the tsunami warnings and immediately after the quake headed for higher ground. Only $5 \%$ of those who attempted to evacuate were caught in the tsunami. Of those who didn't heed the warning, $49 \%$ were hit by water (Japan Times 2011).

The bounded rationality showed itself in the activities of officials in estimating the likelihood of the event as being extremely small. Evidence of bounded rationality includes the actions of the Nuclear and Industrial Safety Agency (NISA), which was aware that structural reinforcement of the power plant is needed to withstand large-scale earthquake and tsunami. Instead of insisting on further reinforcement, NISA was satisfied by the statement that all actions shall be taken by the operator autonomously. By the time of accident, no part of the reinforcement was implemented.

The loss aversion was identified in communication of findings from the scientific community to policy-makers and regulators. Prior to 2011, scientific experts were aware that early warning centres were so ill designed that they would not be usable. It also manifested in the lack of application of the simulation code called SPEEDI, which was designed to estimate the diffusion of radioactive materials. This code could have been used but this did not happen. The major reason for it was that the system was under control of a different authority and people at the plant did not even know that it existed. This would require additional efforts and resources from experts to apply this tool controlled by the different authority. The Tokyo Electric Power Company (TEPCO) was also not reluctant to implement new regulations. The decision-makers at the company assumed that new regulations would make their positions weaker in case of potential lawsuits. This was an example of loss aversion when the probability 
of potential losses from lawsuits were perceived higher then the probability of the event itself. The regulators were also perceiving losses to their reputation from the new regulations. As they had firmly committed themselves to the idea that nuclear power plants were safe, they were reluctant to actively create new regulations. Also, they were part of the Ministry of Economic, Trade and Industry (METI), which is actively promoting nuclear power (Vivoda 2011).

We found evidence of dread risk in statements of the Japanese policy-makers after the Tohoku disaster regarding nuclear technology and possible risks connected with its application (Japan Times 2011).

The existing literature also points to evidence of the limited worry bias, which was manifested in the implementation of regulations regarding nuclear safety. According to the safety procedures, the regulatory agencies would ask explicitly about the intentions of plant operators whenever a new regulation was going to be implemented. But in this case, the regulatory bodies informed the operators that they did not need to consider possible station blackout as the probability of this happening was too small and some preventive measures were already in place. This bias also influenced actions of TEPCO. If the risk factors of tsunami were raised, TEPCO would only look to the risk to their own operations and if it would result in a suspension of existing reactors or would weaken their position in potential lawsuits. However, they had only limited worry about potential risk to public health and welfare.

The experimental versus statistical bias led to false estimations of the probability of earthquakes and therefore improper action by the government. The risk assessment and seismologists estimated that the "big one" earthquake will strike the same place as the 1923 Great Kanto earthquake. The problem was that the Tohoku earthquake had a return period of 1000 years, hence decision-makers didn't have good written records of such a tsunami, although geologists suspected this risk (Lovett 2011; Achenbach 2011).

\section{DISCUSSION AND CONCLUSIONS}

Our first set of results identified cognitive and behavioural biases in decision-making process to 1995 Kobe, 2004 Sumatra-Andaman and 2011 Tohoku earthquakes. The repeatedly available evidence of the biases under all three case studies allows us to make a conclusion that cognitive and behavioural biases are influencing the decision-making process for such critical areas such as multiple hazards risk mitigation. In the absence of relevant expertise decision-makers might be biased towards subjective probability measures.

These results correlate with the scientific literature about the role of risk and uncertainty, which often contains assumption that decision-makers are rational in their assessment of probabilities and making choices. But they also can be a subject of cognitive and behavioural biases to simplify their judgements, they might be risk averse, or myopic, or ambiguous in their decisions. However, in this literature little attention was given to judgments and simplified decision-making rules on risk mitigation measures and how this process is influenced by cognitive and behavioural biases.

The results also correlate with available evidence about particular multi-hazard disasters. For instance, according to the Fukushima Nuclear Accident Independent Investigation Commission, the question was raised about how could such accident as the Fukushima Daiichi Nuclear Power Plant disaster, occur in Japan- a nation that is pride of its global reputation for excellence in engineering and technology. The commission comes to conclusion that the fundamental causes for it are in the behaviour patterns of involved stakeholders, such as reflexive obedience, reluctance to question authority, devotion to sticking with the program, group-ism and insularity (The National Diet of Japan 2012).

Our second set of results showed that availability heuristics, loss aversion and limited worry were three most common biases. The results also showed that the experimental versus statistical evidence and 
bounded rationality are playing least significant role in the decision-making process. We found evidence of dread risk bias only in the case of Tohoku earthquake and only regarding to the nuclear power station. Overconfidence bias was very strong in decision-making prior Tohoku earthquake but not present in Sumatra and Kobe cases (figure 4).

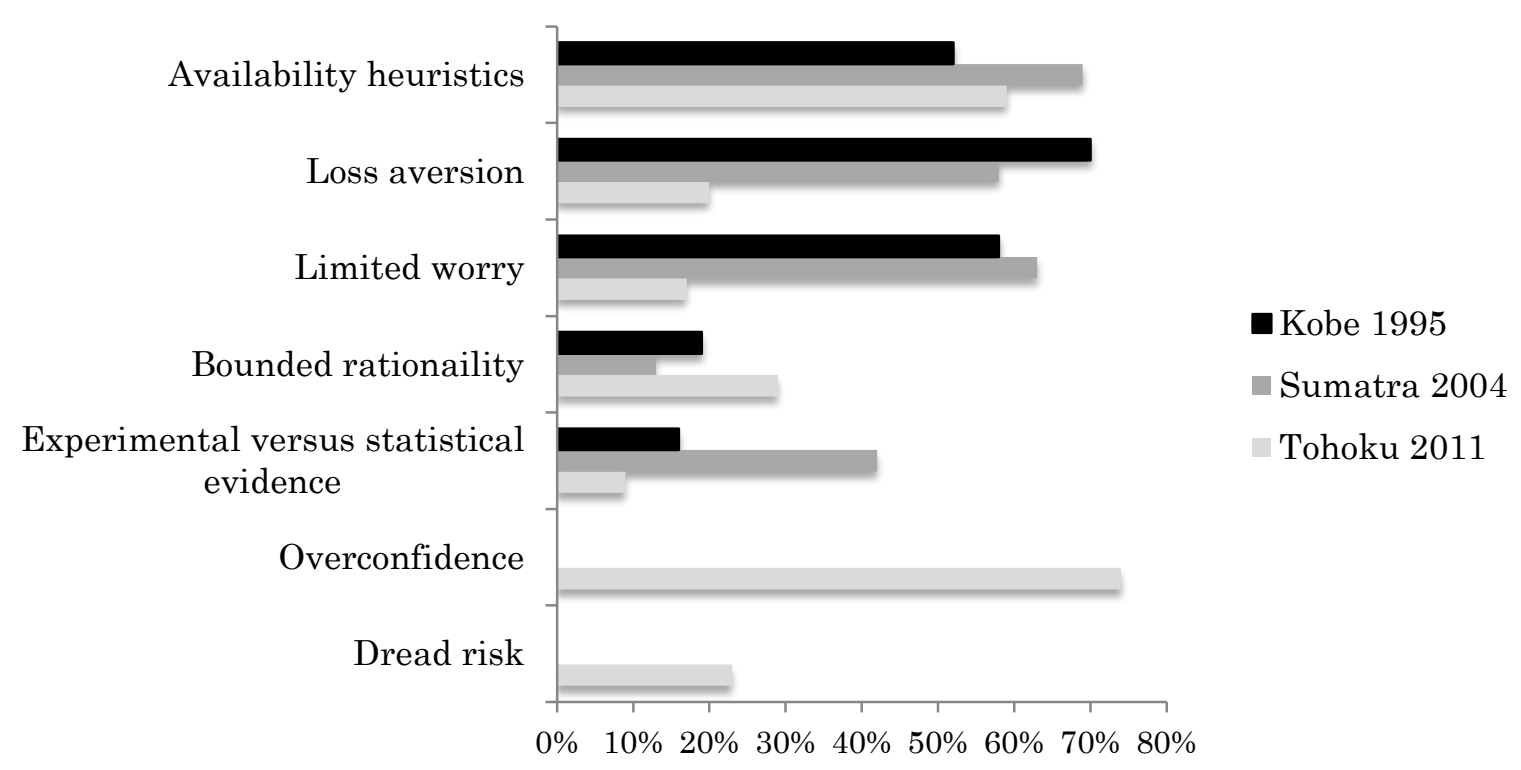

Figure 4. Cognitive and behavioural biases in decision-making processes prior to 1995 Kobe, 2004 Sumatra-Andaman and 2011 Tohoku earthquakes.

Our results support existing research on behavioural economics, in general. As behavioural economics show, the decision-making process is influenced by two systems of the human brain. The perception of statistical information might be different than intuitive and affect-based judgments, which decisionmakers do under time and resources constraints (Kahneman 2011). One system of the human brain is analytical and needs arguments in form of probabilities and risk assessments, scenarios and cost-benefit analysis. This system operates with numbers such as the likelihood of an event in percentages or in monetary terms of costs and benefits of different alternative government interventions. Another system operates with emotional knowledge. The recommendations to address biases in this system include increased transparency of decision-making as well as campaigns to include the level of awareness about the project, its possible risks and benefits. This system of the human brain is an emotional one and is influencing decisions through perceptions. The behavioural economics and decision theory say that cognitive biases manifest themselves automatically and unconsciously over a range of human reasoning and the possible way to mitigate them is to raise awareness of their existence and how they influence the decision-making process in situations of several hazards.

However, they are new to the area of multi-risk governance, which is a relatively new area of analysis in the field, which is until now dominated by engineering sciences. Even if someone is reading through the existing literature on three historical multiple hazards events listed in such databases for peerreviewed papers as Scopus it strikes that the majority of these papers is written in engineering and mathematics, the number of papers published in social sciences on multiple hazards events is minimal. But for natural hazards mitigation decision-makers do not only need arguments in form of probabilities and risks assessment, scenarios and cost-benefit analysis. Also several engineering methods cannot be applied for areas, which are difficult to measure in monetary terms and its also fails to deal with 
catastrophic events, which might lead to unbounded measures of either costs of benefits.

The arguments from practice shall be compelled by scientific knowledge on barriers for implementation of decisions and communication of available engineering knowledge. Therefore, our first recommendation is on urgent need for more research in social sciences on the patterns of natural hazards decision-making processes and governance. The communication process shall address both systems of human reasoning as the analytical arguments and transparent communication from science to decisionmakers can reduce the impacts of behavioural biases.

\section{REFERENCES}

Achenbach, J. (2011) "Japan: The 'Big One' hit, but not where they thought it would". The Washington Post. Archived from the original on 17 March 2011. Retrieved 17 March 2011.

Assmuth, T., Hildén, M., \& Benighaus, C. (2010) Integrated risk assessment and risk governance as socio-political phenomena: A synthetic view of the challenges. Science of the Total Environment, 408, 3943-3953.

Cyranoski, D., (2012) Rebuilding Japan: After the deluge. Japan is rebuilding its coastal cities to protect people from the biggest tsunamis. Nature, Volume 483, March 2012

Dawson, I., Johnson, J., Luke, M., (2012) Do People Believe Combined Hazards Can Present Synergistic Risks? Risk Analysis, Vol. 32, No.5, 2012

Douglas, M . (1985) Risk Acceptability According to the Social Sciences, Russel Sage Foundation, New York.

Durham, K., (2003) Treating the risks in Cairns, Natural Hazards 30(2), 251-261, 2003.

Fleischhauer, M., Greiving, S., \& Wanczura, S. (2007) Territorial planning for the management of risk in Europe. Boletín De La Asociación De Geógrafos Espanoles (Boletín de la A.G.E), 45, 383-388.

Japan Times, (2011). Kyodo News, 90\% of disaster casualties drowned. 21 April 2011, p.2

Garcia-Aristizabal, A., Marzocchi, W., \& Di Ruocco, A. (2013) Probabilistic framework for the assessment of hazard interactions in a multi-risk framework. Deliverable D3.4, new methodologies for multi-hazard and multi-risk assessment methods for Europe (MATRIX project).

Gino, F., Sharek, Z., \& Moore, D. A. (2011) Keeping the illusion of control under control: Ceilings, floors, and imperfect calibration. Organizational Behavior \& Human Decision Processes, 114, 104114

Heath, C., Tversky, A., (1991) "Preference and Belief: Ambiguity and Competence in Choice under Uncertainty", Journal of Risk and Uncertainty, 4, 5-28

Hodder, I., (1994) The interpretation of documents and material culture. In Denzin, K., and Lincoln, Y., (Eds.). Handbook of Qualitative Research. Thousand Oaks, CA: Sage Publications (393-402)

IRGC. (2011) Concept note: Improving the management of emerging risks: Risks from new technologies, system interactions, and unforeseen or changing circumstances. International Risk Governance Council (IRGC), Geneva.

Kahneman, D., (2011) Thinking, fast and slow, Allen Lane Paperback, ISBN 978-1-846-14606-0

Kahneman, D., Tversky, A. (1979) "Prospect theory: An analysis of decisions under risk". Econometrica 47 (2): 263-291. ㅁoi:10.2307/1914185 
Kappes, M. S., Keiler, M., Elverfeldt, von K., \& Glade, T, (2012) Challenges of analyzing multi-hazard risk: A review. Natural Hazards, 64(2), 1925-1958. doi: 10.1007/s11069-012-0294-2.

Katayama, T., Meguro,K., Dutta, D., (2004) "Seismic Risk Management for Countries of the Asia Pacific Region", Proceedings of the 3rd Bangkok Workshop, December 2003. ICUS 2004-01.

Komendantova, N., van Erp N., van Gelder P., Patt, A. (2013) Individual and cognitive barriers to effective multi-hazard and multi-risk decision-making governance. D6.2 MATRIX project.

Kunreuther, H. (2008) "Reducing Losses from Catastrophic Risks Through Long-term Insurance and Mitigation.” Social Research: An International Quarterly 75 (3): 905-930.

Kunreuther, H., R. Ginsberg, L. Miller, P. Sagi, P. Slovic, B. Borkan, and N. Katz (1978) Disaster Insurance Protection: Public Policy Lessons. Wiley Interscience, New York, NY.

Lindblom, C. (1959) The Science Of 'Muddling Through'. In Public Administration Review, Bd. 19 (1959), S. 79-88, ISSN 0033-33529

Lovett, R., (2011) Japan Earthquake Not the “Big One”? National Geographic News. 17 March 2011.

Marx S. M., Weber, E. U., Orlove, B. S., Leiserowitz, A., Krantz, D. H., Roncoli, C., \& Phillips, J. (2007) Communication and mental processes: Experiential and analytic processing of uncertain climate information. Global Environmental Change, 17, 47-58.

Marzocchi, W., Newhall, Ch., \& Woo, G. (2012) The scientific management of volcanic crises. Journal of Volcanology and Geothermal Research, 247-248, 181-189.

Marzocchi, W., Woo, G. (2009) Principles of volcanic risk metrics: theory and the case study of Mt. Vesuvius and Campi Flegrei (Italy). J. Geophysical Research, 114, B03213

Patt, A., Weber, E., (2013) Perceptions and communication strategies for the many uncertainties relevant for climate policy. Wiley Interdisciplinary Reviews: Climate Change. Volume 5, Issue 2, pages 219232, March/April 2014

Plous, S. (1993) The psychology of judgment and decision making. New York: McGraw-Hill.

Renn, O. (2008) Risk governance: Coping with uncertainty in a complex world. London, UK: Earthscan.

Shefrin, H. (2007) Behavioral Corporate Finance. Decisions that Create Value. McGraw- Hill/Irwin. New York, 2007.

Shimazaki, K., (2011) Press conference in Tokyo. India Times, May 12, 2011

Slovic, P. (1987) Perception of risk. Science 236: 280-285

Taylor, S., Brown, J., (1988) Illusion and well-being: a social psychological perspective on mental health. Psychological Bulletin, 103(2), 193-210.

The National Diet of Japan (2012) Published by The Fukushima Nuclear Accident Independent Investigation Commission

Tversky, A., Kahneman, D., (1992) Advances in prospect theory: cumulative representation of uncertainty. In: D. Kahneman und A. Tversky (Hrsg.) Choices, values and frames, Cambridge University Press, Cambridge, S. 44-66.

Tversky, A., Kahneman, D. (1974) "Judgment under uncertainty: Heuristics and biases". Science 185 (4157): 1124-1131. doi:10.1126/science.185.4157.1124

T6. (2007) Assessing and Mapping Multiple Risks for Spatial Planning. Armonia Project deliverable, EU FP6.

Rome:

T6. http://ec.europa.eu/research/environment/pdf/publications/fp6/natural_hazards//armonia.pdf. 
UNISDR. (2005) Hyogo framework for action 2005-2015: Building the resilience of nations and communities to disasters. Retrieved from http://www.unisdr.org/wcdr

UNISDR. (2013) Implementing the HYOGO framework for action in Europe: Regional synthesis report 2011-2013. Retrieved from http://www.unisdr.org/wcdr

Vivoda, V. (2011) Energy Security in Japan. Challenges after Fukushima. ISBN: 978-1-4094-5530-1

White, G., Kates, R., \& Burton, I. (2001) Knowing better and losing even more: the use of knowledge in hazards management. Environmental Hazards, 3, 81-92. 